\title{
Regional Demand For Natural Gas By Electric Utilities
}

\author{
NoEL D. URI*
}

\begin{abstract}
There exists the possibility of interfuel substitution in the generation of electrical energy. The responsiveness of the demand for various fuels by electric utilities given this economic fact is investigated. Using regionally disaggregated data, the results indicate that the responsiveness of the demand for coal, oil, and natural gas by electric utilities to relative price changes is not significant. It is argued that fuel adjustment clauses are responsible for this observation. As expected, the demand for natural gas increases as the level of economic activity expands. Most interesting is the negative response of the demand for natural gas by electric utilities to changes in weather conditions. It is suggested that the reason for this observation is that electric utilities, based on current regulatory practices, are among the first to be curtailed should any supply shortfall occur, given prevailing market conditions.
\end{abstract}

Until recently, research has focused on estimating the elasticity of supply for the primary energy sources particularly crude oil and natural gas. While this is of critical importance to long-run policy, the recent shortages of petroleum products and natural gas underscore the shortterm significance of demand for various energy forms and potentials for interfuel substitution.

The electrical energy industry provides examples of both phenomena. Consumers of electrical energy can substitute other goods (either energy or non-energy goods) for electrical energy in response to changes in relative prices and technology. Additionally, there exists the possibility of interfuel substitution in the generation of electrical energy. It is this second phenomenon that is the subject of this paper.

\section{Background}

Next to oil, natural gas is the nation's largest primary source of energy, accounting for more than 30 percent of current supply. Natural gas has

*The author is an economist with the Federal Energy Administration. The views expressed are those of the author and do not necessarily represent the policies of the Federal Energy Administration or the views of other Federal Energy Administration staff members. 
satisfied the bulk of energy growth in recent years, supplying more than one half of the rising demand for fuels in the 1950's and 1960's.

Recently the gas supply picture has changed. It came as a surprise when in 1970, local gas utilities were compelled to curtail deliveries to some consumers and refuse to sell gas to potential new consumers. The country has entered a period of natural gas shortage which may never be reversed. Natural gas is running short at a time when it is more in demand than ever. The advantage of gas as a clean, environmentally acceptable fuel has made it the most desirable source of energy, and it has also made it scarce.

The scarcity of natural gas has given rise to a series of priorities of deliveries drafted by the Federal Power Commission based on end use. A list of these priorities is found in Table 1. Relative to the question of Federal Power Commission jurisdiction on curtailments, a decision by the U.S. Supreme Court on June 7, 1972, held the Commission has jurisdiction over curtailments in the services of gas in interstate commerce to both resale and direct industrial customers. ${ }^{1}$ This decision reversed a Fifth Circuit Court ruling that immunized direct industrial customers from curtailments.

The establishment of priorities has had a significant impact on the consumption of natural gas by electric utilities. Electric utilities are large users of natural gas with substantial multifuel capabilities. ${ }^{2}$ As a result, they are concentrated in priorities four through nine and consequently are among the first to be curtailed when supply fails to satisfy demand at the prevailing market price.

\section{TABLE 1}

\section{Federal Power Commission Priorities of Deliveries}

1. Residential, small commercial (less than 50 Mcf on a peak day).

2. Large commercial requirements ( 50 Mcf or more on a peak day), firm industrial requirements for plant protection, feedstock and process needs, and pipeline customer storage injection requirements.

3. All industrial requirements not specified in $2,4,5,6,7,8$, or 9 .

4. Firm industrial requirements for boiler fuel use at less than 3,000 Mcf per day, where alternate fuel capabilities can meet such requirements.

5. Firm industrial requirements for large volume (3,000 Mcf or more per day) boiler fuel use, where alternate fuel-capabilities can meet such requirements.

6. Interruptible requirements of more than 300 Mcf per day, but less than 1,500 Mcf per day, where alternate fuel capabilities can meet such requirements.

7. Interruptible requirements of intermediate volumes (from 1,500 Mcf per day through 3,000 Mef per day), where alternate fuel capabilities can meet such requirements.

8. Interruptible requirements of more than 3,000 Mcf per day, but less than 10,000 Mcf per day, where alternate fuel capabilities can meet such requirements.

9. Interruptible requirements of more than 10,000 Mcf per day, where alternate fuel capabilities can meet such requirements. 


\section{Economic Argument}

The demand by electric utilities for natural gas is a derived demand. As such, it is dependent on the demand for electrical energy. Further, not only is the demand for natural gas a function of its own price but also a function of the prices of oil and coal which are substitute fuels for natural gas in the multifuel environment of generating electrical energy via fossil fuels. To the extent fuel adjustment clauses ${ }^{3}$ inhibit the incentive for using the most inexpensive fuel, electric utilities will not be operating in the perfect cost minimizing atmosphere of neoclassical microeconomic theory. It is an observed fact that there is some substitution among fossil fuels in generating electrical energy (Duchesneau (1)). The extent of this substitution in response to price changes, however, needs to be empirically investigated.

It is generally argued that an increase in the demand for a particular good or service will result in an increase in the demand for factors of production used to produce that good or service given that the factors of production are not, in whole or in part, inferior goods. Thus, as the demand for electrical energy increases, for whatever reason, the demand for the imputs used to generate electrical energy would also be expected to increase. Specifically, the demand for natural gas (not being an inferior good) should increase as the demand for electrical energy increases. An empirical test follows in an effort to validate this hypothesis.

\section{A Demand Model}

In the short-run, the demand for natural gas by electric utilities is determined primarily by the price of natural gas, price of substitute fuels, and the demand for electrical energy by the various consumer classes. Given the short-run nature of the outlook, the components of the demand for electrical energy by consumer classes that are highly variable in the short-run are used as proxies for the demand for electrical energy.

The functional form is log-linear where the logarithm of the quantity of natural gas demanded is a linear function of the logarithm of the prices of the various fuels, the logarithm of degree days ${ }^{4}$ which is used as proxy for the seasonal demand for electrical energy by residential, commercial and industrial consumers, and the logarithm of the index of industrial production which is used as a proxy for the level of economic activity which will affect the general level of demand for electrical energy (5, Chapter 2). The resultant coefficients are interpreted as the responsiveness of the quantity demanded for natural gas by electric utilities in percent to a one percent change in the specific variable. Thus, the responsiveness of the quantity demanded of natural gas to, say, a ten percent increase in degree days, will be the coefficient on the logarithm of degree days times ten. 
Because coal and oil are substitute fuels for natural gas and hence will affect the quantity of natural gas demanded, the quantities of oil and coal demanded are specified as functions of the same five variables.

Summarily, the demand for natural gas and its substitute fuels is modeled as follows:

$$
\text { (1) } \begin{aligned}
\log \mathrm{D}_{\mathrm{it}} & =\beta_{0}+\beta_{1 \mathrm{i}} \log \mathrm{PGAS}_{\mathrm{t}}+\beta_{2 \mathrm{i}} \log \mathrm{POIL}_{\mathrm{t}} \\
& +\beta_{3 \mathrm{i}} \log \mathrm{PCOAL}_{\mathrm{t}}+\beta_{4 \mathrm{i}} \log \mathrm{DD}_{\mathrm{t}} \\
& +\beta_{5 \mathrm{i}} \log \mathrm{IP}_{\mathrm{t}}+\varepsilon_{\mathrm{it}}
\end{aligned}
$$

where $D_{i t} \quad$ for $i,=1,2,3$ is the demand for natural gas, oil, and coal by electric utilities, respectively, in period $t$

PGAS $_{t}$ is the price of natural gas to electric utilities in pe$\operatorname{riod} \mathrm{t}$

POIL $_{t} \quad$ is the price of oil to electric utilities in period $t$

PCOAL $_{t}$ is the price of coal to electric utilities in period $t$

$\mathrm{DD}_{t} \quad$ is the number of heating degree days in period $t$, $\mathrm{IP}_{\mathrm{t}} \quad$ is the index of industrial production in period $t$, $\beta_{1 \mathrm{i}}, \beta_{21}, \ldots, \beta_{5 \mathrm{i}}$ are unknown parameters, and

$\varepsilon \quad$ is the error term

\section{The Data}

The demand for natural gas by electric utilities is examined here at the census region level. The composition of the regions is detailed in Table 2.

TABLE 2

Regional Classification

\begin{tabular}{ll}
\hline \multicolumn{1}{c}{ Region } & \multicolumn{1}{c}{ Composition } \\
\hline 1. New England & $\begin{array}{l}\text { Maine, New Hampshire, Vermont, Massachusetts, } \\
\text { Rhode Island, Connecticut }\end{array}$ \\
2. Middle Atlantic & $\begin{array}{l}\text { New York, New Jersey, Pennsylvania } \\
\text { Ohio, Indiana, Illinois, Michigan, Wisconsin } \\
\text { 3. East North Central }\end{array}$ \\
4. West North Central & $\begin{array}{l}\text { Minnesota, Iowa, Missouri, North Dakota, South } \\
\text { Dakota, Nebraska, Kansas }\end{array}$ \\
5. South Atlantic & $\begin{array}{l}\text { Delaware, Maryland, District of Columbia, Virginia, } \\
\text { West Virginia, North Carolina, South Carolina, }\end{array}$ \\
6. East South Central & $\begin{array}{l}\text { Georgia, Florida } \\
\text { 7. Wentucky, Tennessee, Alabama, Mississippi } \\
\text { 8. Mountain }\end{array}$ \\
Arkansas, Louisiana, Oklahoma, Texas \\
9. Pacific & $\begin{array}{l}\text { Montana, Idaho, Wyoming, Colorado, New Mexico, } \\
\text { Arizona, Utah, Nevada }\end{array}$ \\
& Washington, Oregon, California
\end{tabular}


Monthly observations of each variable in a region cover the period January 1972 through December 1975. The electric utility fuel consumption data were obtained from the Monthly Power Plant Report distributed by the Federal Power Commission. The delivered prices of the fuels were obtained from the Monthly Report of Cost and Quality of Fuels for Steam Electric Plants also distributed by the Federal Power Commission. The heating degree day data were supplied by the National Weather Service on a state basis. A weighted average of the state data (weighted by each state's contribution to total fossil-fuel generation in a region) was constructed to arrive at the regional degree day data. The index of industrial production was obtained from the seasonally unadjusted series reported in the Federal Reserve Bulletin which is issued monthly. The exact specifications of the variables can be found in Table 3 . Note that the concept of demand being used here is actual consumption and consequently curtailments of natural gas to electric utilities are imbedded in the values.

\section{Estimation of the Demand Model}

The responsiveness of the demand by electric utilities for each of the three fossil fuels by electric utilities in a region to changes in the explanatory factors was estimated using the iterative, seemingly unrelated regression techniques of Zellner (6). This approach was used to permit the imposition of a cross-equation symmetry constraint on the industrial production coefficients while at the same time capturing the effects of factors influencing all equations not otherwise incorporated into the specification. Without the cross-equation symmetry constraint, the seemingly unrelated regression estimates would reduce to ordinary least squares estimates. In addition such a constraint makes economic sense because changes in the level of economic activity should not favor the use of one fuel over another in generating electrical energy.

\section{Empirical Results}

The log-linear demand model was fitted to data for the period January 1972 through December 1975. Each region was treated separately. The regression results are presented in Table 4 . The values in parentheses are the standard errors of the estimates. Not surprisingly, the responsiveness of the demand for coal, oil, and natural gas by electric utilities to changes in prices of fossil fuels is not consistently significant in any of the nine regions considered. ${ }^{8}$ Because of the existence of fuel adjustment clauses in all but five states ${ }^{5}$ that permit electric utilities to pass on to consumers any change in the price of fuels, there is, in the aggregate, no incentive for utilities to utilize the cheapest fuel. Fuel adjustment clauses encourage use of fuels covered by the clause and construction of plants burning those fuels, and thus discourage development of alternative energy sources. Fuel adjustment clauses move the major component of generating expenses-fuel costs-from rate case proceedings where the 
TABLE 4

Estimates of Coefficients of Demand Equations

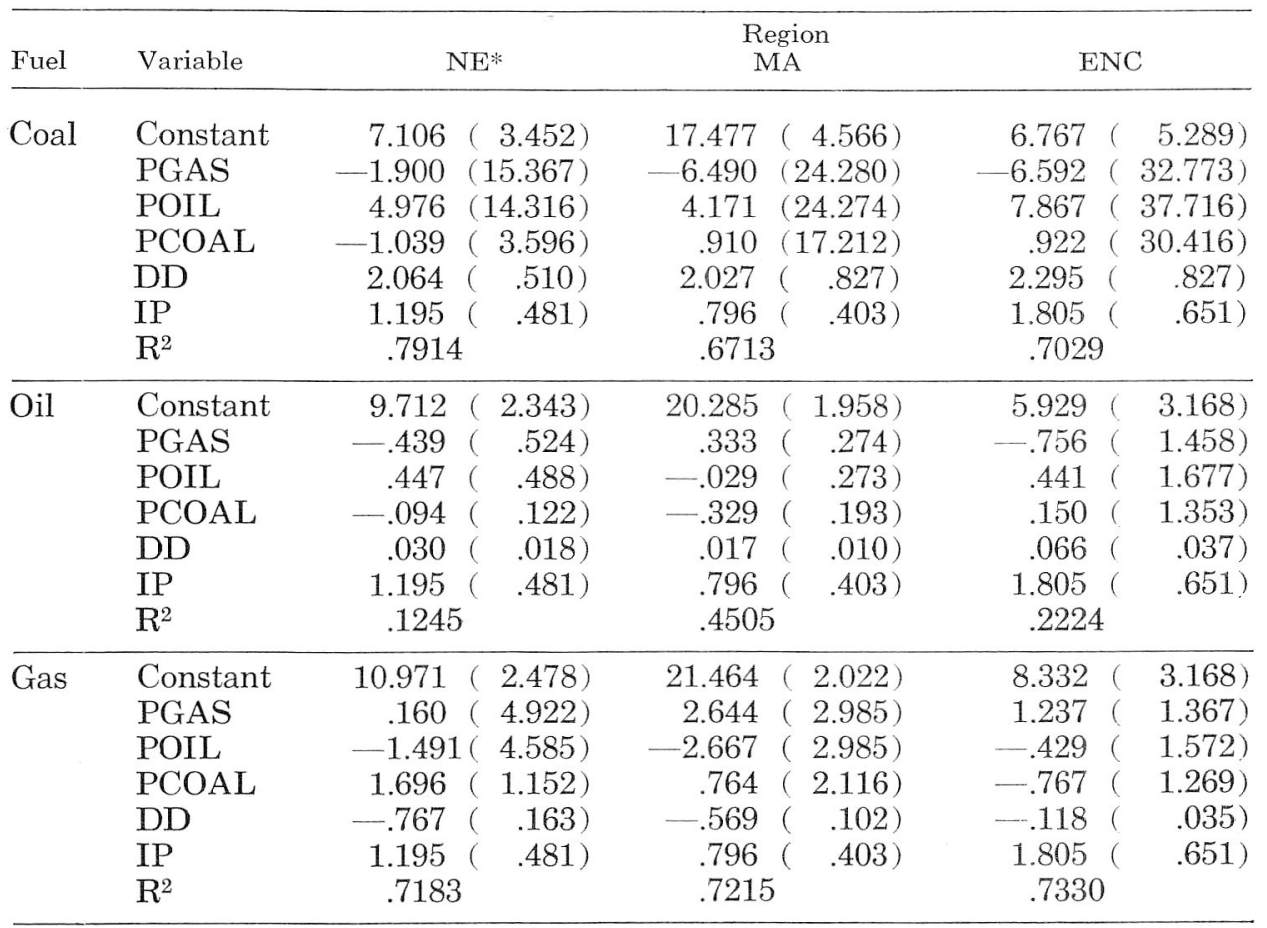

*NE denotes the New England region, MA denotes the Middle Atlantic region, and so on.

utility is subject to cross-examination by commission staffs and protestants. Thus, as long as the fuel adjustment clauses persist, one can expect to continue observing the lack or response by utilities to changing. relative fuel prices.

Given the focus of the considerations is on the demand for natural gas by electric utilities with specific reference to demand responsiveness to weather conditions, the comments hereafter are limited to natural gas considerations. Discussions of the other fossil fuels would follow an analogous path. Demand response to the level of economic activity yields the expected outcome. Thus, as the economy expands, the demand for natural gas (as well as other fossil fuels) expands. The results are statistically significant at the 5 percent level for all regions with the exception of the South Atlantic region.

The most interesting result and the one that runs contrary to a priori expectations is the consistently significant ${ }^{6}$ negative response in each region of the demand for natural gas by electric utilities to changes in the temperature. As the weather becomes more severe with a corresponding increase in the demand for electrical energy by consumers, electric 
TABLE 4 (cont'd)

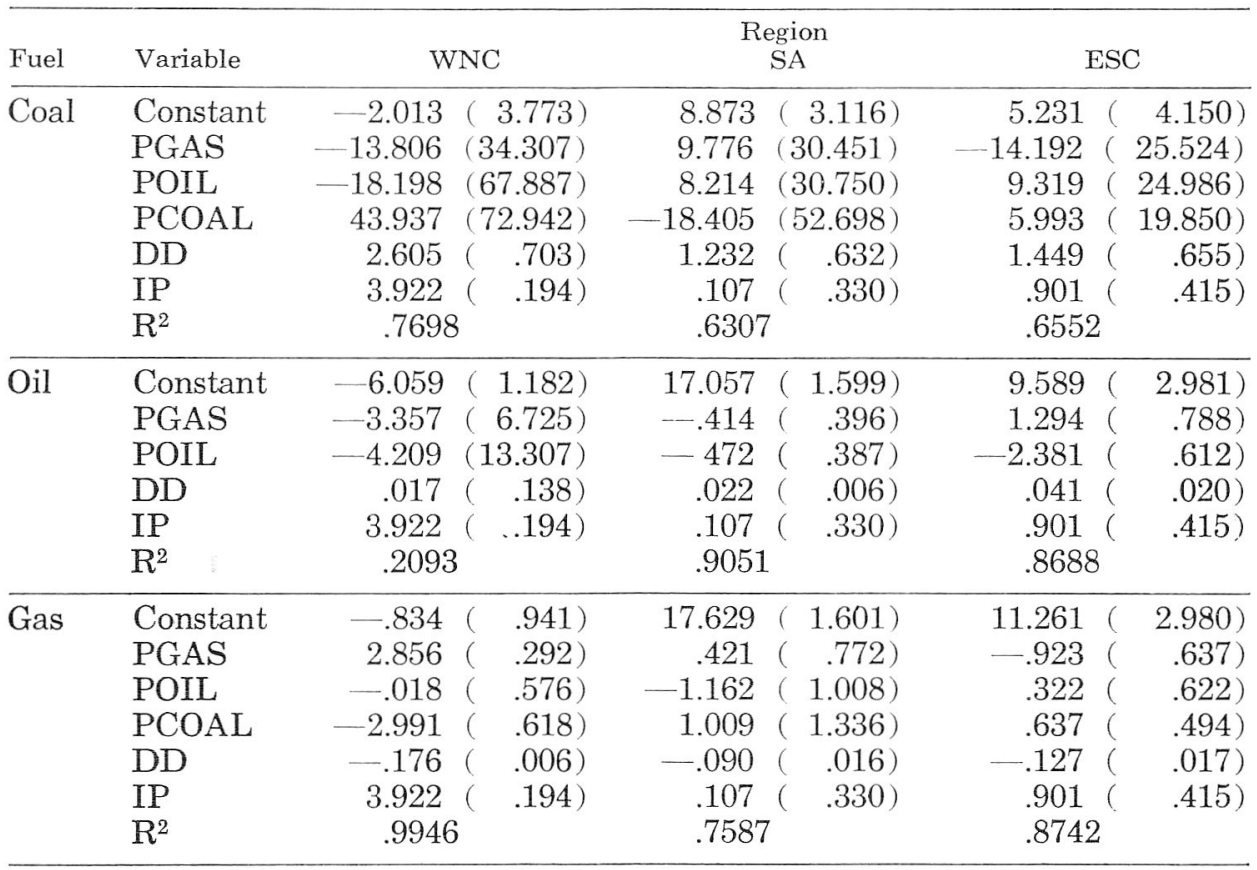

utilities consume less natural gas. This is inconsistent with the economic argument of Section II. A reconciliation is needed.

It will be recalled from the previous discussion that due to the scarcity of natural gas, curtailment of deliveries to some consumers has arisen. Curtailments occur in descending order of Federal Power Commission priorities. Because electric utilities are most heavily concentrated in priorities 4 through 9 (See Table 1), they will be curtailed before most other users. What this means is that as weather conditions become more severe, not only do the residential and commercial consumers demand more electrical energy, they also demand more natural gas. The result is that there is less natural gas available for electric utilities to use for generation so one witnesses a change to an alternate fuel. In the aggregate, electric utilities are required to forego consumption of natural gas to the benefit of the residential and commercial consumers as weather conditions worsen. Further, as one moves away from the gas producing regions (the East South Central and the West South Central), the responsiveness of the demand for natural gas by electric utilities, on the average, to weather changes increases. ${ }^{7}$

\section{Summary}

There exists the possibility of interfuel substitution in the generation of electrical energy. The responsiveness of the demand for various fossil fuels by electric utilities given this economic fact has been investigated. 
TABLE 4 (cont'd)

\begin{tabular}{|c|c|c|c|c|}
\hline Fuel & Variable & WSC & $\begin{array}{l}\text { Region } \\
\text { IMTN }\end{array}$ & $\mathrm{PC}$ \\
\hline Coal & $\begin{array}{l}\text { Constant } \\
\text { PGAS } \\
\text { POIL } \\
\text { PCOAL } \\
\text { DD } \\
\text { IP } \\
\mathrm{R}^{2}\end{array}$ & $\begin{array}{rr}10.527 & (2.901) \\
-23.108 & (27.954) \\
.204 & (17.167) \\
20.624 & (29.982) \\
1.156 & (.458) \\
.782 & (.465) \\
.6696 & \end{array}$ & $\begin{array}{rr}15.664 & (5.074) \\
-19.952 & (32.262) \\
16.122 & (21.458) \\
-1.009 & (13.623) \\
3.180 & (.899) \\
.919 & (.395) \\
.7642 & \end{array}$ & $\begin{array}{rr}21.0238 & (7.109) \\
50.521 & (311.796) \\
-106.357 & (565.038) \\
96.314 & (465.000) \\
2.052 & (1.327) \\
1.593 & ( \\
.5875 & \end{array}$ \\
\hline Oil & $\begin{array}{l}\text { Constant } \\
\text { PGAS } \\
\text { POIL } \\
\text { PCOAL } \\
\text { DD } \\
\text { IP } \\
\mathrm{R}^{2}\end{array}$ & 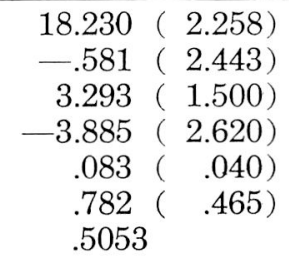 & 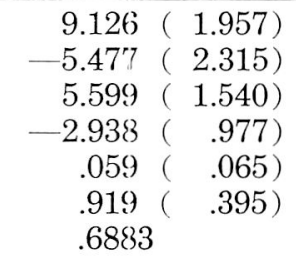 & 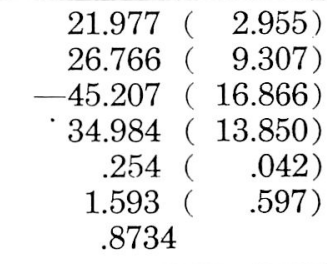 \\
\hline$\overline{\mathrm{Gas}}$ & $\begin{array}{l}\text { Constant } \\
\text { PGAS } \\
\text { POIL } \\
\text { PCOAL } \\
\text { DD } \\
\text { IP } \\
\text { R }^{2}\end{array}$ & 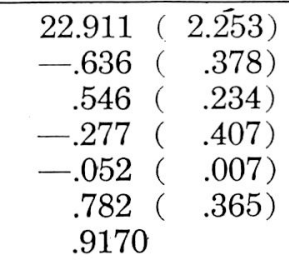 & 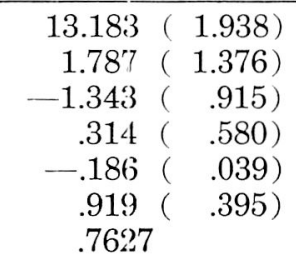 & $\begin{array}{rr}27.010 & (3.000) \\
-20.701 & (26.582) \\
40.885 & (48.172) \\
-34.829 & (39.558) \\
-.464 & \left(\begin{array}{r}114) \\
1.593(\end{array}(.597)\right. \\
.6889 & \end{array}$ \\
\hline
\end{tabular}

Using regionally disaggregated data, the results indicated that the responsiveness of the demand for coal, oil, and natural gas by electric utilities to relative price changes is not sigrificant. It is argued that fuel adjustment clauses are responsible for this observation. As expected, the demand for natural gas increases as the level of economic activity expands. Most interesting was the negative response of the demand for natural gas by electric utilities to changes in weather conditions. It is suggested that the reason for this is that electric utilities, based on current regulatory practices, are among the first to be curtailed should any shortfall occur, given prevailing market conditions.

\section{FOOTNOTES}

1'The U.S. Supreme Court in FPC vs. Louisiana Power and Light Co. 406 U.S. 621.

2.As an example, slightly more than 50 percent of total generating capacity had multifuel capability in 1972 while only 5.8 percent of total capacity had gas (single fuel) capability.

3 Fuel adjustment clauses are provisions in a utility company's rate schedule which allows a change in fuel costs to be automatically (i.e., with commission hearings) reflected in rates charged customers.

${ }_{4}^{4}$ Heating degree day is a unit measuring the extent to which the outdoor mean (average of the maximum and minimum) daily dry-bulb temperature falls below $65^{\circ} \mathrm{F}$. One degree day is counted for each degree of deficiency below $65^{\circ} \mathrm{F}$, for each calendar day.
5 Minnesota, Oregon, Washington, Montana, and Idaho have no fuel adjustment clauses in the tariffs of regulated utilities.

6 At the $1 \%$ level.

7The coefficient on temperature is probably biased upward. This is due to the use of only heating degree days as the temperature proxy. Had cooling degree days also been used the coefficient on heating degree days might have become absolutely smaller. The bias, however, is probably not large enough to reverse the sign of the coefficient. Cooling degree data were not used because they were not available.

$8 \mathrm{Lag} g$ ed values of the prices were also used with the lag varying up to 18 periods. They similarly proved to be insignificant. 


\section{REFERENCES}

1. T. Duchesneau, Interfuel Substitutability in the Electric Utility Sector of the U.S. Economy, Washington, 1972.

2. Federal Power Commission, Monthly Power Plant Report, Washington, monthly.

3. Federal Power Commission, Monthly Report of Cost and Quality of Fuels for Steam-Electric Plants, Washington, monthly.

4. Federal Reserve Board, Federal Reserve Bulletin, Washington, monthly.

5. N. D. Uri, Towards An Efficient Allocation of Electrical Energy, Lexington, 1975.

6. A. Zellner, "An Efficient Method of Estimating Seemingly Unrelated Regressions and Tests for Aggression Bias", The Journal of The American Statistical Association, Vol. 57 (June 1962) pp. 348-368. 